\title{
VIRTUAL REALITY: DEVELOPING A VR SPACE FOR ACADEMIC ACTIVITIES
}

\author{
D. Kaimaris *, E. Stylianidis, N. Karanikolas
}

AUTh, School of Spatial Planning and Development (Eng.), Thessaloniki, Greece - (kaimaris, sstyl, karanik)@auth.gr

\author{
Technical Commission V
}

KEY WORDS: Virtual reality, Panoramas, Education

\begin{abstract}
:
Virtual reality (VR) is extensively used in various applications; in industry, in academia, in business, and is becoming more and more affordable for end users from the financial point of view. At the same time, in academia and higher education more and more applications are developed, like in medicine, engineering, etc. and students are inquiring to be well-prepared for their professional life after their educational life cycle. Moreover, VR is providing the benefits having the possibility to improve skills but also to understand space as well. This paper presents the methodology used during a course, namely "Geoinformatics applications" at the School of Spatial Planning and Development (Eng.), Aristotle University of Thessaloniki, to create a virtual School space. The course design focuses on the methods and techniques to be used in order to develop the virtual environment. In addition the project aspires to become more and more effective for the students and provide a real virtual environment with useful information not only for the students but also for any citizen interested in the academic life at the School.
\end{abstract}

\section{INTRODUCTION}

During the period of the first Greek Republic, with Prime Minister Alexandros Papanastasiou, Thessaloniki hosted the headquarters of the second University of Greece in 1925, the "University of Thessaloniki", as originally named. Thirty (30) years later the establishment of the Faculty of Engineering (1955) was realised; having first the School of Civil Engineering. In following years, we had the establishment of other Schools, such as the School of Architecture, School or Rural and Surveying Engineering, School of Chemical Engineering, School of Mechanical Engineering, School of Electrical and Computer Engineering, and finally the School of Spatial Planning and Development (Eng.) in 2004 (AUTh, 2013).

VR is extensively used in various industrial applications; in fact, it is becoming more and more reasonable for the end users. VR is extensively used in medical applications (Riener and Harders, 2012), in aerospace applications (Stone et al., 2011) but also in entertainment (Hsu, 2011). We also do have examples in education (Sampaio et al., 2010), like the one we are discussing in this paper.

The use of panoramas is widespread in creating virtual museums, representation of tourist facilities (e.g. hotel), etc. In the paper we discussed the used of $360^{\circ}$ panoramas and appropriate software (Tourweaver ${ }^{\mathbb{B}}$ ) (Easypano Holdings Inc, 2013) for creating the first virtual academic space for the Faculty of Engineering, Aristotle University of Thessaloniki (AUTH). The School of Spatial Planning and Development (Eng.) in its attempt to enable students' participation by giving access throughout its facilities at the Faculty of Engineering developed the virtual School of Spatial Planning and Development (Eng.). Visitors to this virtual space can navigate in all classrooms, be informed about the courses conducted in each classroom, navigate the ICT labs, the secretariat, the Library as well as at the offices of the academic staff.

Specifically, the virtual School of Spatial Planning and Development (Eng.) enables:

- visit the exterior and interiors School's spaces;
- selection between six specific routes (academic staff offices, secretariat, library, teaching (Wing A), teaching (Wing B), teaching (Wing C), which start from the main entrance of the Faculty of Engineering, permit optimal user navigation within the Faculty and smooth navigation towards the area of interest);

- spatial contiguous information of each stop;

- reporting of the curriculum for each classroom

\section{DESIGNING THE VIRTUAL SCHOOL}

The Faculty of Engineering is located in the University campus (Figure 1). The School of Spatial Planning and Development (Eng.) is using areas (Table 1) in the ground floor of the main building for hosting academic staff offices and the secretariat as well (Figure 2, index D). The School is hosting the classrooms and the amphitheaters on Wings A, B and C, as illustrated in Figure 2 at the 1st, 2nd or 3rd floor. In addition, on the 3rd floor of Wing C, the School is hosting the two ICT labs, which are used both for teaching purposes and students' activities. The library is located on the 2nd floor of building C (Figure 2).

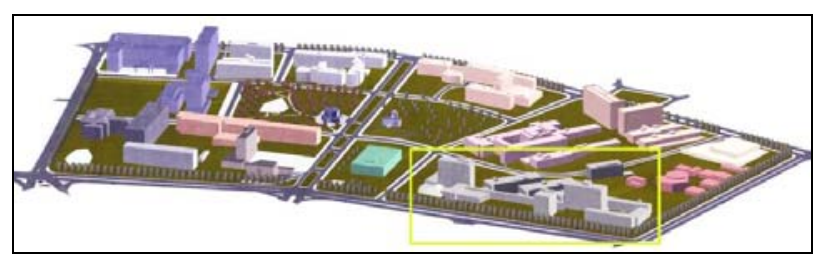

Figure 1: The University campus and the Faculty of Engineering (in yellow frame) 


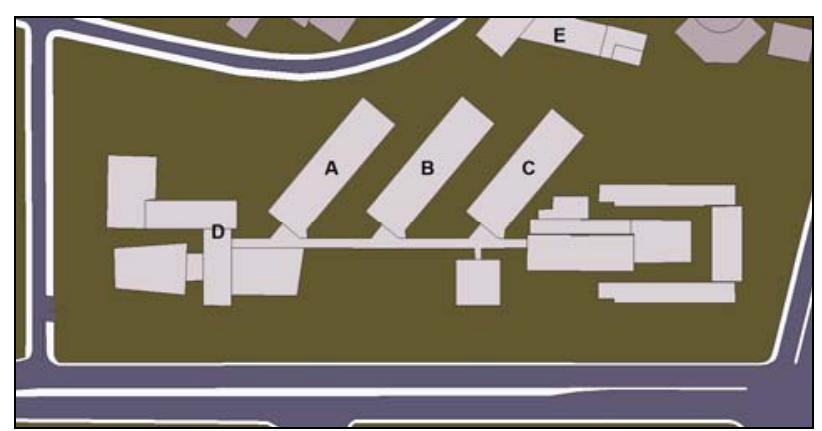

Figure 2. The Faculty of Engineering and the buildings coding

\begin{tabular}{|l|c|c|c|c|c|}
\hline & $\begin{array}{l}\text { Wing } \\
\text { A }\end{array}$ & $\begin{array}{l}\text { Wing } \\
\text { B }\end{array}$ & $\begin{array}{l}\text { Wing } \\
\text { C }\end{array}$ & $\begin{array}{l}\text { Building } \\
\text { D }\end{array}$ & $\begin{array}{l}\text { Buildin } \\
\text { g E }\end{array}$ \\
\cline { 2 - 6 } & \multicolumn{5}{|c|}{ No. } \\
\hline $\begin{array}{l}\text { Class- } \\
\text { rooms }\end{array}$ & 4 & 5 & 3 & - & - \\
\hline $\begin{array}{l}\text { Audi- } \\
\text { toriums }\end{array}$ & 1 & 1 & 1 & - & - \\
\hline ICT labs & - & - & 2 & - & - \\
\hline Library & - & - & - & - & 1 \\
\hline $\begin{array}{l}\text { Academic } \\
\text { staff } \\
\text { offices }\end{array}$ & - & - & 8 & - & - \\
\hline Secretariat & - & - & - & & - \\
\hline
\end{tabular}

Table 1. The spaces of School of Spatial Planning and Development (Eng.)

For creating the virtual School, six different and independent access paths have been implemented: one for the academic staff offices' area (Figure 3), one for the Secretariat (Figure 4), one for Wing A at the Faculty premises (Figure 5), one for Wing B at the Faculty premises (Figure 6), one for Wing $\mathrm{C}$ at the Faculty premises (Figure 7) and one for the library (Figure 8). From Table 1 as well as from Figures 3 to 8, comes up that the School is using a total of 27 rooms; for this reason is necessary to introduce 39 additional (shooting) stops (external response, stops outside rooms, wings, etc.), in order to have a smooth and virtual transition in the every room of interest.

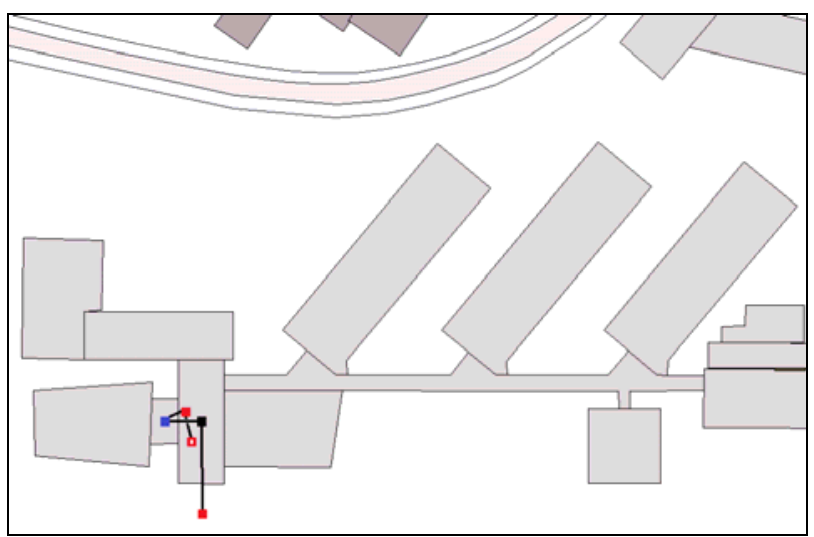

Figure 3. Academic staff offices path. $\mathbf{q}$ Ground floor, $\mathbf{\square} 1^{\text {st }}$ floor, $\square$ Half-pace, $\square$ Offices.

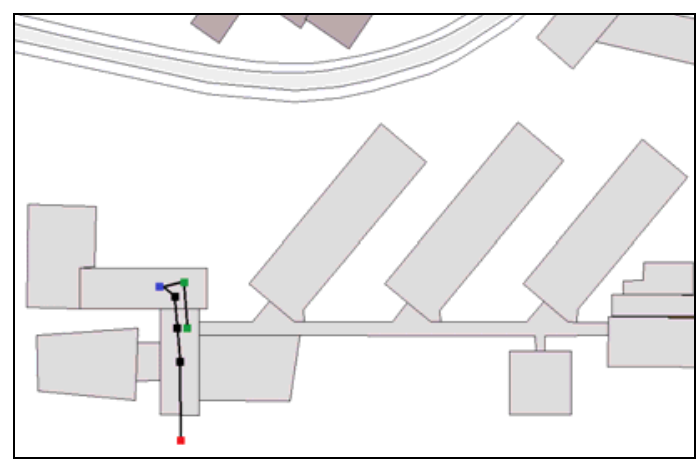

Figure 4. Secretariat path. $\square$ Ground floor, $\mathbf{a} 1^{\text {st }}$ floor, $\square$ Halfpace, $\square 2^{\text {nd }}$ floor.

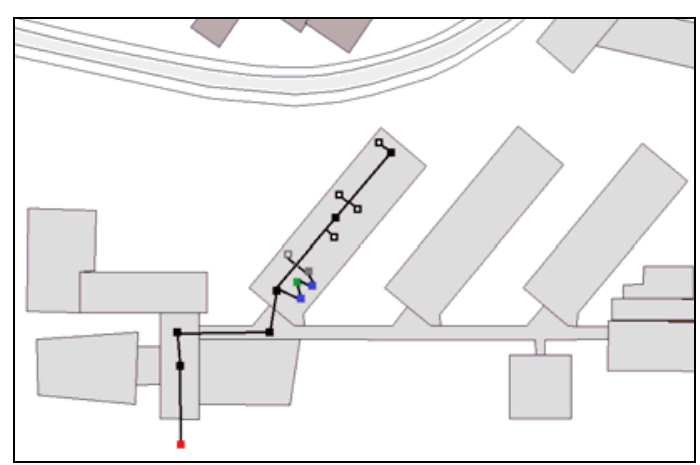

Figure 5. Wing A path. $\square$ Ground floor, $\mathbf{\square} 1^{\text {st }}$ floor, $\boldsymbol{\square}$ room or amphitheatre, $1^{\text {st }}$ floor, $\square$ Half-pace, $\square 2^{\text {nd }}$ floor, $3^{\text {rd }}$ floor, $\square$ room or amphitheatre, $3^{\text {rd }}$ floor.

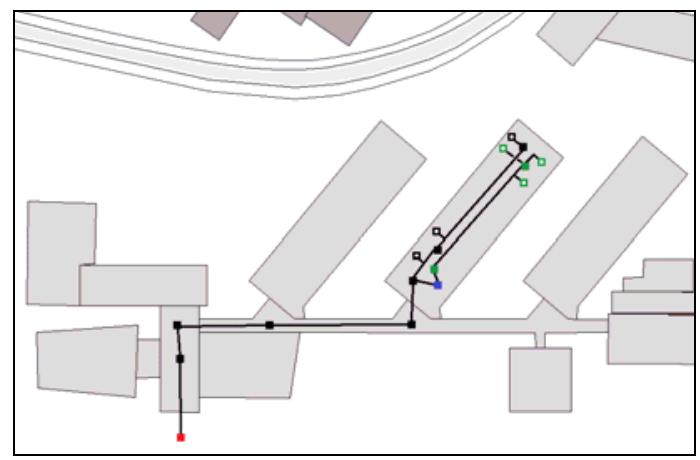

Figure 6. Wing B path. $\square$ Ground floor, $\square 1^{\text {st }}$ floor, $\boldsymbol{\square}$ room or amphitheatre, $1^{\text {st }}$ floor, $\square$ Half-pace, $\square 2^{\text {nd }}$ floor, $\square$ room or amphitheatre, $2^{\text {nd }}$ floor.

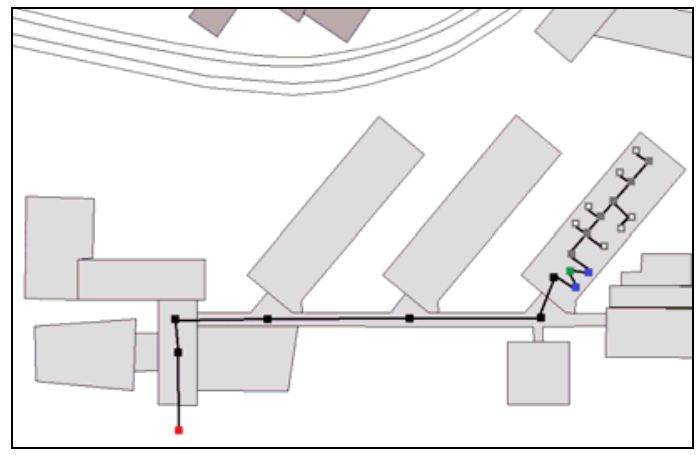

Figure 7. Wing C path. Ground floor, $\mathbf{\square} 1^{\text {st }}$ floor, $\square$ Halfpace, $\square 2^{\text {nd }}$ floor, $\square 3^{\text {rd }}$ floor, $\square$ room or amphitheatre, $3^{\text {rd }}$ floor. 


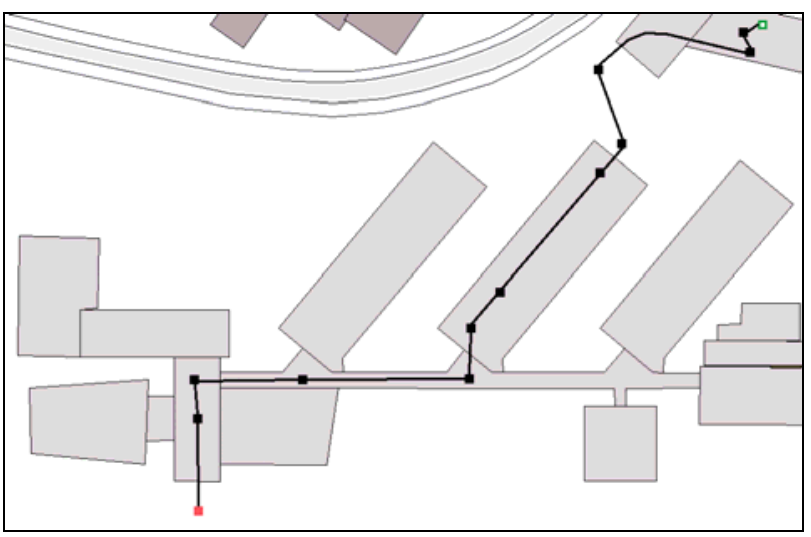

Figure 8. Secretariat path. $\square$ Ground floor, $1^{\text {st }}$ floor, $\square$ Library, $2^{\text {nd }}$ floor

\section{IMAGE ACQUISITION}

A panorama is a wide-angled view of a physical space captured by the images. In fact, a panorama is usually several images that are stitched together horizontally to create a one-piece picture.

In our case, a total of 66 panoramas were captured using:

- a digital camera Canon EOS 20D of 8Mpixel (DpReview, 2013);

- a tripod;

- a tape measure;

- a plumb;

- an electronic compass (Konig, 2013).

After mounting the camera on the tripod, the height of $\sim 1.6 \mathrm{~m}$ was chosen as camera height for image shooting. The tripod is allowing the placement of the camera in portrait shooting position (Figure 9), so as in each image does have the largest possible area of the object while capturing.

Each panorama is implemented by 18 images having an overlap of $30-60 \%$ (depending on the distance of the shooting object/area from the camera), which were captured in the horizontal plane every 20 degrees. This was achieved by using an electronic compass to facilitate the process.

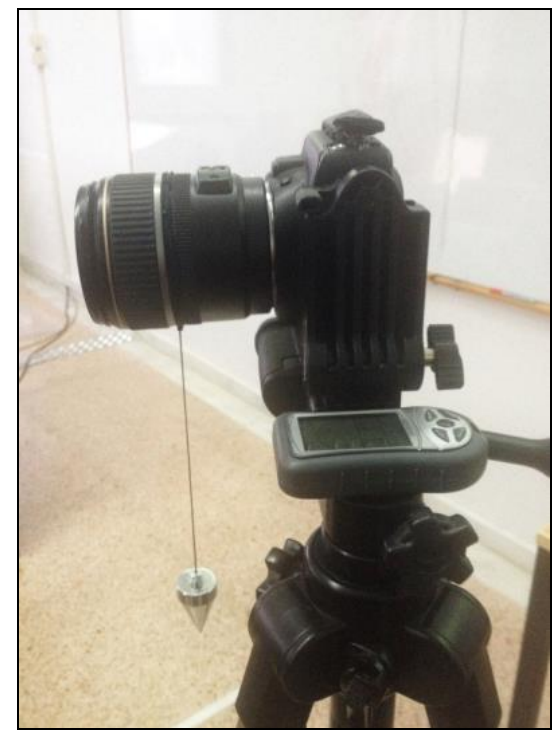

Figure 9. Camera position over the tripod, the plump line and the electronic compass.
The plumb line was placed (approximately) at the focal lens centre (Figure 9). With this assumption, the x-parallax between consecutive shots of the same panorama was zero, allowing the optimal image stitching during panorama production. Besides, the plumb line secures the maintaining the focal lens centre position during the horizontal rotation of the tripod. For this reason, initially, a fixed point on the ground was selected for each panorama. In each tripod's horizontal rotation, the point's position was chosen in such a way that the imaginary extension of the plumb line coincides with the fixed point on the ground as illustrated in Figure 10.
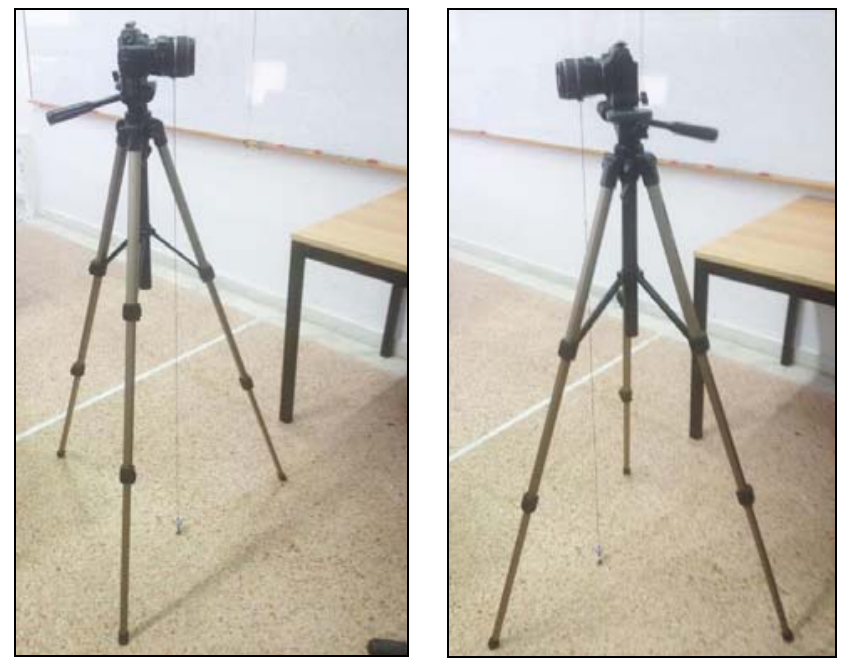

Figure 10. Image acquisition; keeping constant the same ground point at each shoot.

A total of 1188 images were captured for this project while 66 panoramas have been created in total to cover all spaces used by the School.

\section{PANORAMA CREATION}

In order to create the panorama Adobe Photoshop CS6 ${ }^{\circledR}$ (Adobe Systems Software Ireland Ltd, 2014) was used. Specifically, the Photomerge tool was chosen for this reason. The cylindrical development and images' stitching selected as the appropriate layout. The panorama production maintains both the vertical and horizontal surface of the presented object (Figure 11, Figure 12). Furthermore, in order to correct problems appear in stitched images, additional tools, such Clone Stamp and Smudge, are used to improve the image quality.

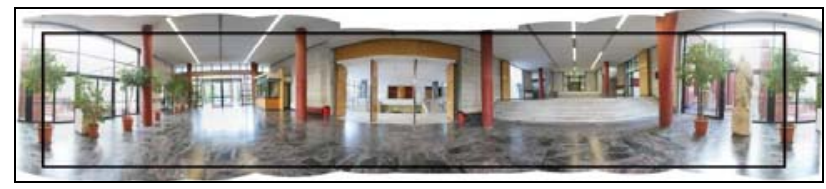

Figure 11. The initial panorama; the area within the black frame illustrates the useful area in vertical and 360o horizontally.

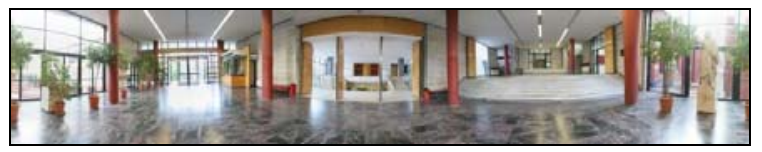

Figure 12. The final panorama. 


\section{THE 'VIRTUAL SCHOOL'}

Tourweaver ${ }^{(\mathbb{R}}$ was used as the software tool for developing the virtual school's infrastructure. In order to do so, the software demands the introduction of the panoramas, the map indicating the locations of the panoramas, the navigation tools, etc.

By enabling virtual school the user is seated at the main gate of the Faculty of Engineering (Figure 13). The navigation tools are positioned at the bottom of the screen to assist user's navigation. Starting from left to right (Figure 13), there is a Home button (starting from the main gate at the Faculty of Engineering), Go to previous panorama, Go to next panorama, Turn left, Turn right, Move up, Move down, Zoom in, Zoom out, Switch to full screen and Map. These are the navigation tools offered to the user.

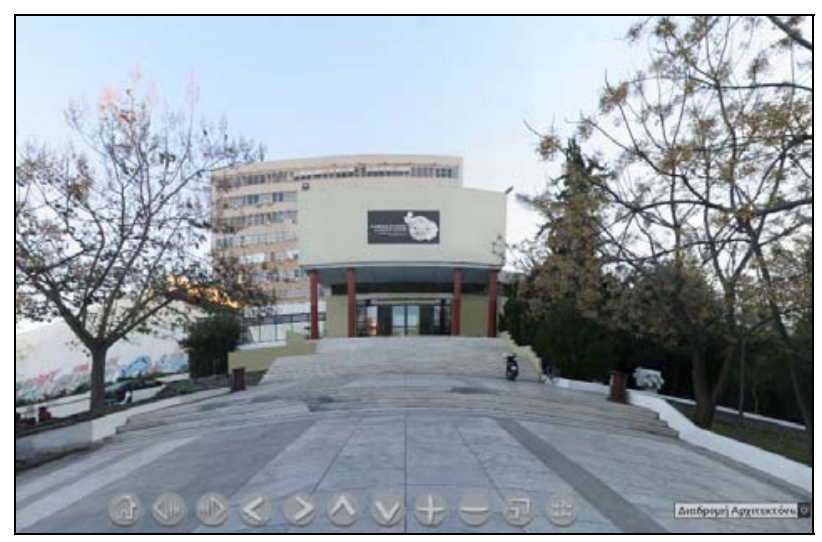

Figure 13. The starting interface.

Selecting the Map button, the transparent map, as illustrate in Figure 14, appears on the screen. At the bottom right of the screen, a slider provides the opportunity to navigate in selected paths of potential interest: secretariat route, Wing A route, Wing $B$ route, Wing $C$ route, library route. For each path, the application isolates and shows only the panoramas which constitute the specific path. The positions of the panoramas are displayed in different colours (depending the floor) on the map, while the move to the next or previous panorama is feasible either by buttons Go to the next panorama or Go to previous panorama, or by selecting with the cursor over the map panorama of interest).

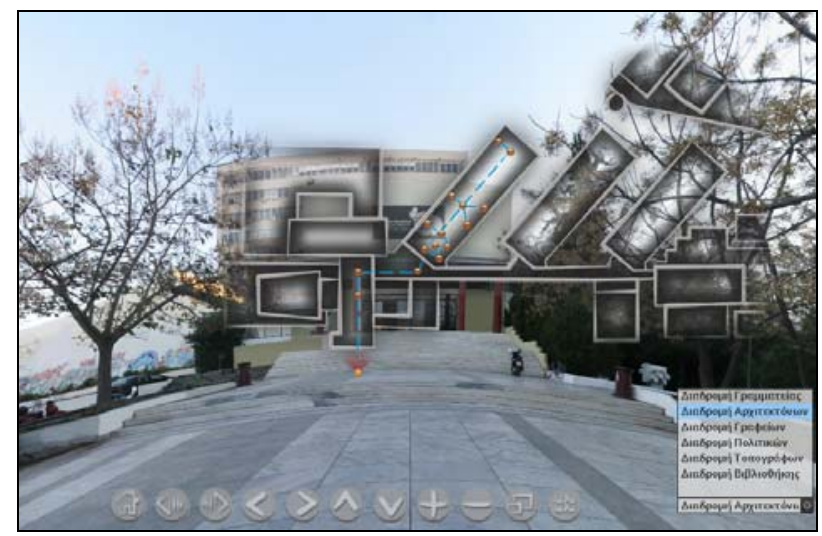

Figure 14. Map appearance over the initial screen and the paths for selection.
The user can move to the next or previous panorama by selecting either the man's figure appeared on the screen (Figure 15) or a door appeared in the image and the user aspires to enter a new space (e.g. offices).

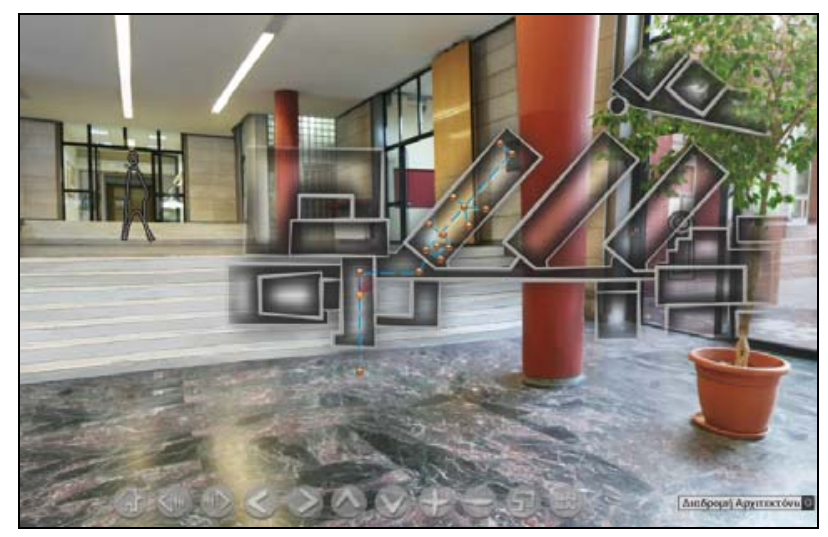

Figure 15. The man's figure in the next panorama position.

The radar, displayed as field of view, over the map in the panoramas position is useful to facilitate user's orientation in the surrounding space (Figure 16).

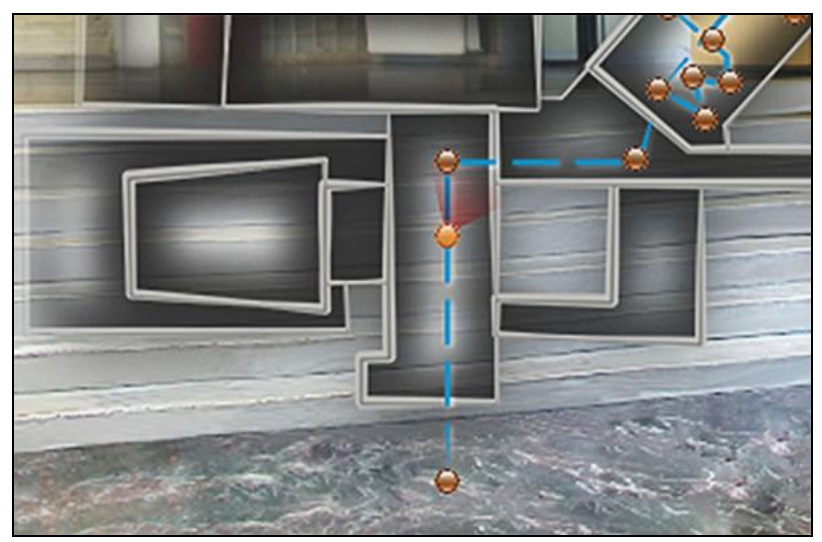

Figure 16. The radar for user's orientation.

By passing the cursor over the man's figure or the information symbol (i), the relevant information is shown (Figure 17).

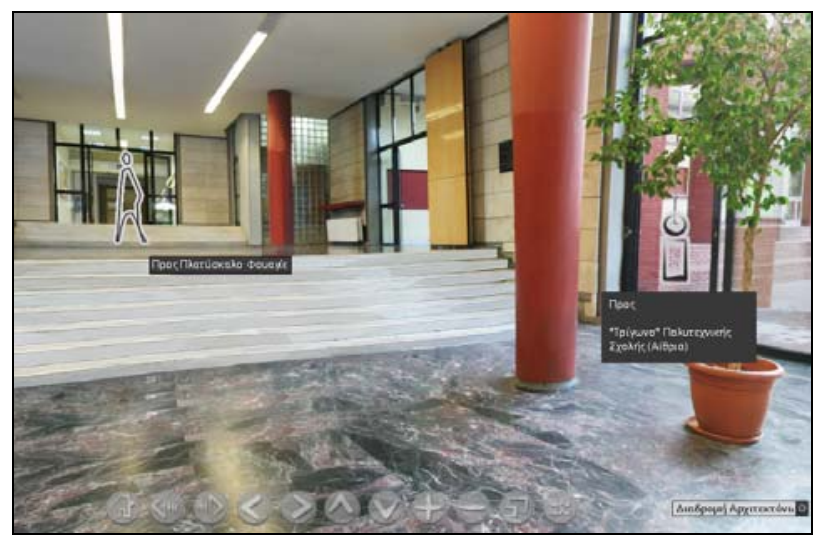

Figure 17. Information appears when the cursor is over of specific symbols.

In the 66 panoramas presented, outstanding sculptures created by the academic staff and students are hosted in the Faculty of 
Engineering. The user has the opportunity to 'visit' these exhibits virtually (Figure 18). In addition, in each room or amphitheater detailed information of offered courses is illustrated (Figure 19).

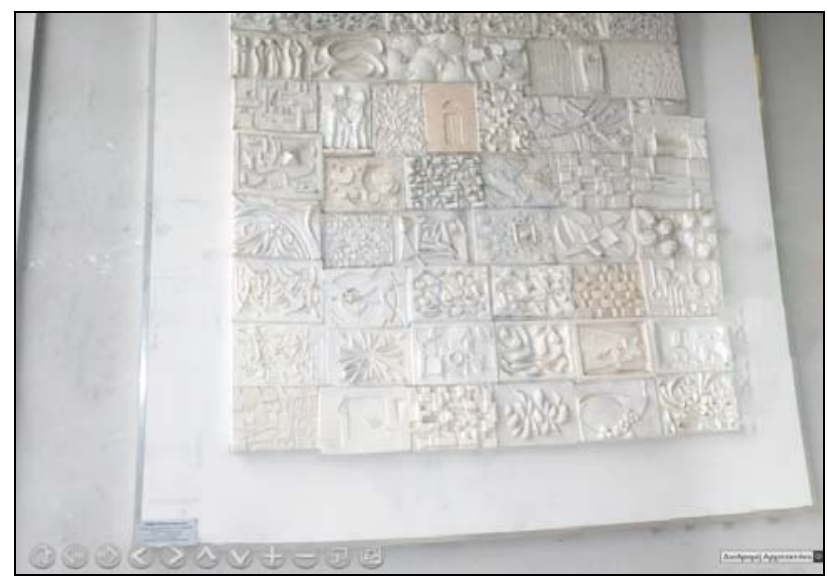

Figure 18. Anaglyph students' project at the School of Architecture
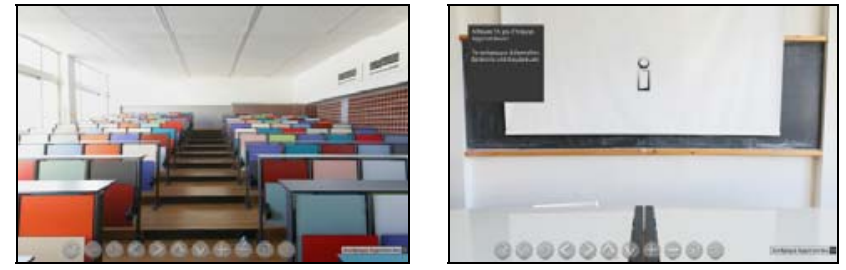

Figure 19. An amphitheater from the blackboard (left); the information symbol (i) provides access to the list of offered courses.

The Virtual School platform is available and runs in all common browsers, such as Mozilla Firefox, Google Chrome and Internet Explorer. Preferably, the platform was designed for the Mozilla Firefox.

\section{CONCLUSIONS AND FUTURE WORK}

VR is growing. It has many application fields starting from computer science, to culture, aerospace but also in education. For engineers seems to be an important topic. VR collaboration platforms are giving the opportunity not only to present a space but also to interact with people and activities taking place in this space.

During the project, which was implemented during an academic semester, the students had the opportunity to explore, learn and present the space spending many hours of their daily activities. The teaching team have noticed that the challenging tasks of the project taken place during the course "Geoinformatics applications" strongly motivate the students. The motivation in the various students' teams prepared to implement the project, increases so much that most students often work on the project in their spare time.

The paper presents the work done for creating the first VR School in the Aristotle University of Thessaloniki, School of Spatial Planning and Development (Eng.), Greece. At this first stage, we have created the critical infrastructure for presenting the spaces that the School is active. But the project aspires to go a step further. The plans for the next period include the introduction of more information (educational programme, activities, schedules, etc.) in the VR system in order to become a real working tool for the educational activities at the School while at the same time to give the opportunity to every user all over the world to come in touch with the academic life at the School.

\section{REFERENCES}

Adobe Systems Software Ireland Ltd, 2014. Adobe Photoshop family, http://www.adobe.com/mena en/products/photoshop family.html, (04 March 2014).

AUTh, 2013. Faculty of Engineering, http://www.eng.auth. gr/gr/archiki/i-polytechniki-scholi. html, (04 March 2014).

Riener, R. and Harders, M., 2012. Virtual Reality in Medicine. Springer London.

DpReview, 2013. Cannon EOS 20D, http://www.dpreview .com/reviews/canoneos20d, (04 March 2014).

Easypano Holdings Inc, 2013. Virtual Tour Software, http://www.easypano.com/virtual-tour-software.html, March 2014).

Hsu, K. S., 2011. Application of a Virtual Reality Entertainment System with Human-Machine Sensor Device. Journal of Applied Sciences, 11, pp. 2145-2153.

Konig, 2013. KN-CP40, http://www.itsmart.gr/pdf/MANUAL KN-CP40_COMP.pdf, (04 March 2014).

Sampaio, A., Henriques, P., Martins, O., 2010. Virtual Reality Technology Used in Civil Engineering Education. The Open Virtual Reality Journal, 2, pp. 18-25.

Stone, R. J., Panfilov, P. B., Shukshunov, V. E., 2011. Evolution of aerospace simulation: From immersive Virtual Reality to serious games. In: 5th International Conference on Recent Advances in Space Technologies (RAST), pp. 655-662.

\section{ACKNOWLEDGEMENTS}

The paper is based on the work done during the course "Geoinformatics applications", at the $7^{\text {th }}$ semester of academic year 2013-2014, at the School of Spatial Planning and Development (Eng.), AUTh. 